\title{
Conceptual Study of Production Technology of Free-Form Concrete Segments
}

\author{
Donghoon Lee, Won-Kee Hong, Jeong Tai Kim, and Sunkuk Kim
}

\begin{abstract}
Free-form designs are increasing which is beyond a simple design form to meet the requirements of clients wishing to improve the building value and of the government for symbolic buildings. Furthermore, development of construction technologies, materials and equipment has led to production and installation of free-form concrete. However, unlike the fixed form, free-form concrete requires more time and manpower. In particular, mold for production of free-form materials can be used only once, which implies that excessive resources are input for mold manufacturing. This may result in reduced productivity, increased cost and extended construction duration. It is necessary to develop technologies that can solve the limitation in relation to cost, time, quality and safety so as to ensure economic feasibility and constructability of the free-form buildings. In this regard, the study intends to analyze the problems of producing free-form concrete and construction using such concrete, and to conduct a conceptual study on the technology that is capable of solving the problems. The study draws the requirements of production technology of free-form concrete, and proposes the production technology that can solve the existing problems.
\end{abstract}

Index Terms-Free-form concrete segment, production technology, mold manufacturing, free-form designs.

\section{INTRODUCTION}

The types of free-form buildings and related technologies are evolving [1]. Especially, when the latest free-form buildings are compared with the ones of the past, the types and developed technologies can be seen [2]. This is because development of computer science, materials and equipments has led to improved designs and construction technologies, and that has enabled production of a wide range of free-form concrete. Despite the fact there has been dramatic development in modern construction technologies, there still exists difficulties in producing free-form buildings associated with automatic creation of designs, panelization, manufacturing and measurement [3].

In terms of the materials, the free-form type is more economical when compared with other construction materials such as metals and stones, and it is easy to be molded and manufactured. In addition, the outer part of a complicated free-form building cannot be built in such a large scale, so it should be segmented. This free-form concrete segment can be easily and quickly assembled depending on the applied joint method, and the thickness and finished surface can be realized depending on the structural

Manuscript received June 1, 2014; revised July 25, 2014.

The authors are with the Donghoon Lee is with the Dept. of Architectural Engineering, Kyung Hee Univ., 1732 Deogyeong-dearo, Giheung-gu, Yongin-si, Gyeonggi-do, Korea (e-mail: donghoon@khu.ac.kr, hongwk@khu.ac.kr, jtkim@khu.ac.kr, kimskuk@khu.ac.kr) strength and finishing type, which may solve the existing problems of free-form buildings.

Manufacturing mold for production of free-form concrete is more time and labor consuming than that for fixed types. Moreover, since the mold is used only once for various types of free-form material pouring, excessive materials, manpower and time are required, and it is difficult to be reused and leads to reduced productivity. However, there are many problems related to cost and construction duration that are not solved yet, as the concrete material is applied to free-form buildings (quoted from the dissertation of Geun-ho Kim).

The studies regarding production of free-form concrete include adoption of Computerized Numeric Control (hereinafter referred to as "CNC") by P. Mandl et al., [4] and Lindsey and Gehry [5] for EPS-formwork and timber system processing by Toyo Ito \& Associates [6] for production of free-form concrete. Latorre [7] used the pneumatic system to come up with a free-form dome, and Verhaegh [8] used the fabric formwork to produce free-form concrete. The study conducted by Park et al. [9] adopted CNC-processed $\mathrm{T}$-shaped light weight steel to develop a construction method that is capable of securing constructability, economic-feasibility and technical power of free-form concrete area. Franken Architeckten \& Abb Architeckten [10] used a digital mold that is applied with CNC and acryl glass to produce free-form concrete. In other words, CNC-processed steel, wood, EPS and textile forms were used. However, the previous studies focused on production of free-form concrete and its superiority, lacking information on ensuring economic feasibility. Thus, studies on a variable mold that can be reused are required. The study aims for 'Conceptual Study of Production Technology of Free-form Concrete Segments' by analyzing the existing technologies and providing a direction for development of an enhanced production technology of free-form concrete.

First of all, the existing methods of producing free-form concrete and their problems are examined. Secondly, the necessary and development conditions of a variable mold that can be reused for solving the problems identified are drawn for improvement and the direction of mold development is proposed. Thirdly, the improved mold is used to suggest technologies of shaping free-form concrete and manufacturing molds, casting methods and production processes.

The study takes into consideration of the production technology of free-form member that is applied with concrete as a material. In addition, the study scope ranges from production after 3D designs to development of technologies on CNC-applied variable molds and casting. In this regard, 
the study analyzes the technical requirements and problems of free-form concrete production technology to solve the existing production problems, and proposes the development concept of free-form concrete production technology that is capable of ensuring constructability and economic feasibility. The study result will be used as basic data for comparison/analysis studies on economic-feasibility and constructability of the existing molds and the improved ones, and for free-form concrete production to build free-form buildings.

\section{PRELIMINARY StUdy}

To produce free-form concrete, Timber system, Pneumatic system, Fabric formwork, EPS-formwork, 3D printing and so forth are used [11]. Several studies and experiments related to free-form concrete applied with the methods mentioned above are as following.

Using CNC processing method, P. Mandl et al., [12] and Lindsey and Gehry[8] produced the EPS-formwork and Toyo Ito \& Associates[13] developed the timber system to come up with free-form concrete. The CNC-processed molds can accurately shape concrete for construction, yet they cannot be reused, which certainly needs to be solved. Latorre [5] adopted the pneumatic system to build a free-form dome. The materials should be individually processed to come up with such free-form shape, and there was no additional study on producing other various shapes, which needs to be done. The study conducted by Verhaegh [11] is on free-form concrete using the fabric formwork, yet it needs additional studies on reusing flexible fabric and reinforcement method. Moreover, numerous molds are used for geometric constraint of fabric and the time required for manufacturing the molds should be shortened. The study performed by Park et al. [14] is on development of the method that can ensure constructability, economic-feasibility and technical power of free-form concrete area by using the CNC-processed T-shaped light weight steel. However, the study is in its early stage without details, so in-depth study is required. Franken Architeckten \& Abb Architeckten [4] used a digital mold applied with $\mathrm{CNC}$ and acryl glass to express the surface stress of water drops, in order to produce free-form concrete. However, the preliminary studies focused on production of free-form concrete and its superiority, lacking information on ensuring economic feasibility. Thus, studies on a variable molds that can be reused are required.

IMCRC (Innovative Manufacturing and Construction Research Centre) of Loughborough University in England is studying the 3D Printing Method to produce free-form concrete [6]. There are 2 types of mold used - Master Moulds and Direct Moulds. Master Moulds divide a large concrete panel and Direct Moulds pour the concrete to a mold to come up with the basic free-form concrete shape. 3D Printing is performed on top of this basic panel shape to produce free-form concrete. It needs technologies to avoid repetitive manufacturing of different shaped molds and additional manpower input for finishing works.

The previous studies on production of free-form concrete have not taken into consideration of constructability and economic-feasibility. Thus, it is necessary to develop production technologies of variable molds and free-form concrete through reuse of molds and minimization of manpower input to the process.

\section{ANALysis ON THE EXISTING PRODUCTION TECHNOLOGIES OF FREE-FORM CONCRETE}

\section{A. EPS Formwork}

In case of EPS mold, the mold is shaped using 3D-CAD and EPS blocks that are processed using NC are assembled and installed. On the top of the installed EPS blocks, free-form concrete is produced [2], [8].

Spencer Dock Bridge [2] worked on the concrete which is poured after production and installation of EPS mold for around 6 months [8]. The quality of concrete surface was outstanding, but the joint grid of EPS blocks left unnecessary lines on the concrete surface as shown in Fig. 1.

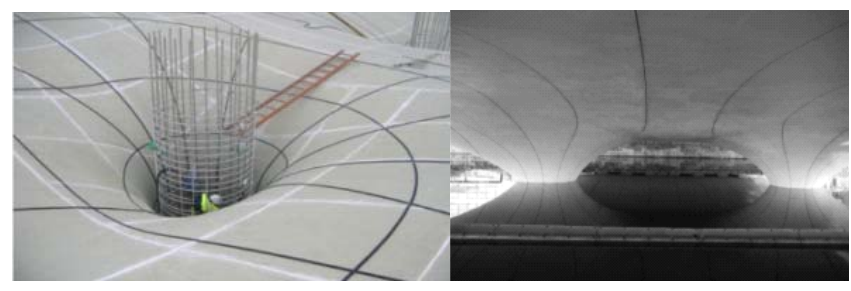

Fig. 1. Spencer dock bridge and underside of spencer dock bridge [3], [13].

\section{B. Wooden and Steel Formwork}

Mercedes Benz Museum used a precise mold made of wood and steel that is prefabricated through digital master model and CNC processing [15], [16]. In addition, a smooth curve of EPFL Learning Center that is $7,500 \mathrm{~m}^{2}$ in size is produced using about 1,500 wooden molds and standard scaffolding [17]. In case of such in-situ production molds, the temporary resources cannot be reused as shown in Fig. 2 and they are difficult to be manufactured, resulting in inevitable cost increase. In addition, it requires a lot of time for manufacturing.

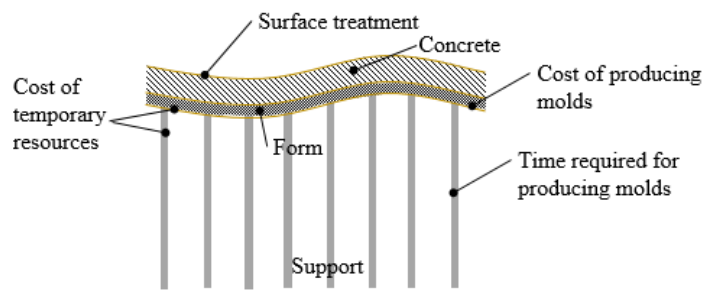

Fig. 2. Problems of the in-situ production forms.

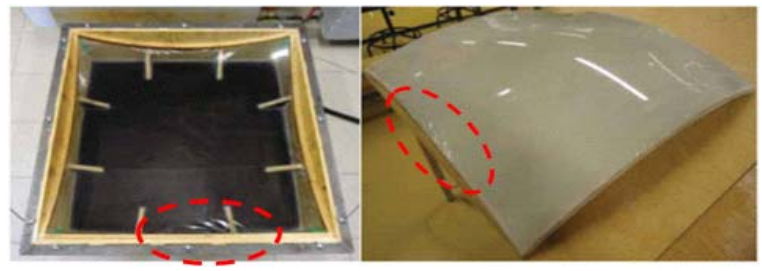

Fig. 3. Crease on the corner of textile mold [18].

\section{Textile Formwork}

When it comes to textile molds, it is difficult to ensure uniform thickness and angle of given segments. Therefore, if 
inaccurate design or construction is done, defects may occur. As illustrated in Fig. 3, there may be crease in the corner, resulting in a significant structural error.

\section{CNC-Based Formwork}

$\mathrm{CNC}$ is a method of producing any shape using a computer without depending on the manual operation of people [19]. CNC-based mold production can be divided into cutting, formative and subtractive depending on the production method as shown in Table I [20].

TABLE I: CNC BASED MOLD PRODUCTION TECHNIQUES

\begin{tabular}{|c|c|c|c|}
\hline Description & Linear cutting & Bending & 3 -axis cutting \\
\hline $\begin{array}{l}\text { Production } \\
\text { method }\end{array}$ & $\begin{array}{l}\text { Linear-cutting } \\
\text { members by using } \\
\text { numeric controlled } \\
\text { data }\end{array}$ & $\begin{array}{l}\text { Heating \& bending } \\
\text { members by using } \\
\text { numeric controlled 3D } \\
\text { data }\end{array}$ & $\begin{array}{l}\text { 3-axis-cutting } \\
\text { members by } \\
\text { using numeric } \\
\text { controlled 3D } \\
\text { data }\end{array}$ \\
\hline Material & $\begin{array}{l}\text { Plate type materials } \\
\text { (steel, plastic, stone, } \\
\text { etc.) }\end{array}$ & $\begin{array}{l}\text { Plate type materials } \\
\text { (metal, plastic, wood, } \\
\text { etc.) }\end{array}$ & $\begin{array}{l}\text { Mass type } \\
\text { materials (metal, } \\
\text { plastic, stone, } \\
\text { wood, etc.) }\end{array}$ \\
\hline Tools & $\begin{array}{l}\text { laser beam, water } \\
\text { jet, plasma-arc }\end{array}$ & $\mathrm{CNC}$ bending machine & $\begin{array}{l}3 \text {-axis milling } \\
\text { machine }\end{array}$ \\
\hline
\end{tabular}

Camera Obscura is a free-form building constructed using the mold produced with a laser cutter. The digital data extracted from the computer model were used to fabricate aluminum and steel components and then they were assembled for construction [20], [21]. In addition, in case of Big Belt House, the shape was predesigned using a computer to create a curve shape of hill, and the mold was produced at the factory using a 3-axis CNC milling machine. Then, the concrete was poured on site for construction [21]. However, the CNC-based molds produced up to now cannot be reused and it takes a longer production time. Thus, fundamental consideration of the mold materials should be made, and new technologies should be developed.

\section{E. $3 D$ Printing}

Use of 3D printer is a new technology in producing free-form concrete members. However, it has a limitation in that it cannot be adopted for producing large-scale construction materials.

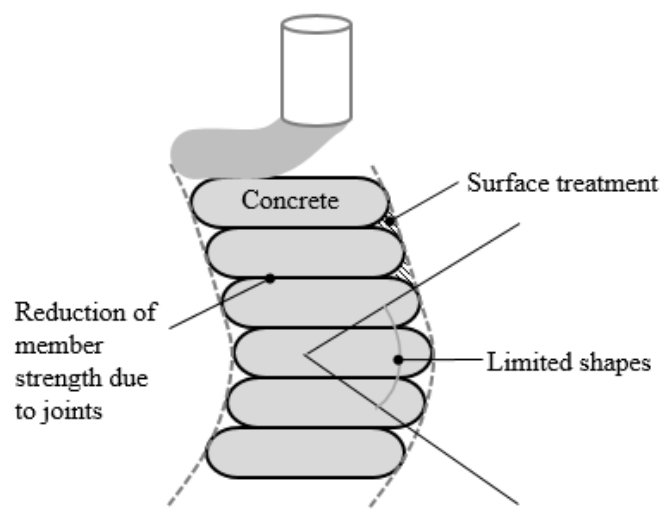

Fig. 4. Problems of 3D printing technique.

Since several layers of concrete should be connected as shown in Fig. 4, a lot joints are inevitable, which may result in reduced strength and leakage. Moreover, post-treatment such as plastering of the rough surface with jagged shape after production is required. At last, it may collapse if printing is done when the concrete is not hardened yet, and various shapes cannot be realized.

\section{DIRECTION OF THE IMPROVED FREE-FORM CONCRETE PRODUCTION TECHNOLOGY}

In this study proposed the following requirements for producing the molds to produce free-form concrete as shown in Table II.

TABLE II: THE REQUIREMENT ON PRODUCTION TECHNOLOGY OF FREE-FORM CONCRETE

\begin{tabular}{|c|c|c|c|}
\hline Type & \multicolumn{2}{|c|}{ Materials } & Requirements \\
\hline $\begin{array}{l}\text { Free-Form } \\
\text { Concrete } \\
\text { Segments } \\
\text { (FCS) }\end{array}$ & \multicolumn{2}{|c|}{$\begin{array}{l}\cdot \text { GFRC } \\
\text { (Press, Plaster method) } \\
\cdot \text { HPC/UHPC } \\
\text { (Grouting method) }\end{array}$} & $\begin{array}{l}\text { Economic feasibility, } \\
\text { constructability, } \\
\text { durability, strength, } \\
\text { watertightness, } \\
\text { mixture and } \\
\text { insulation } \\
\text { performance }\end{array}$ \\
\hline \multirow[t]{2}{*}{$\begin{array}{l}\text { Production } \\
\text { Equipment } \\
\text { (Variable } \\
\text { Mold) }\end{array}$} & Components & $\begin{array}{l}\cdot \text { Memory alloy } \\
\cdot P C M \\
\text { (Phase Change } \\
\text { Material) }\end{array}$ & \multirow[t]{2}{*}{$\begin{array}{c}\text { Productivity, } \\
\text { economic-feasibility, } \\
\text { convenience, } \\
\text { variability, reusability } \\
\text { and finishability }\end{array}$} \\
\hline & $\begin{array}{l}\text { Composed } \\
\text { Equipment }\end{array}$ & $\begin{array}{l}\text { CNC machine } \\
\cdot \text { Back-up rod }\end{array}$ & \\
\hline
\end{tabular}

To satisfy the requirement on production technology of free-form concrete, the following 6 matters should be met. First, upon mass-production, the curing speed of concrete and economic feasibility should be good. Second, constructability should be good for realization of accurate shapes. Third, since it is used as finishing materials, it should be capable of enduring external pressure, and there should not be any element causing quality degradation. Fourth, the materials that are reusable should be used for manufacturing molds for production of concrete members, and they should be economical as well. Fifth, molds should vary for mass production of a wide range of shapes or forms, and they should be quickly produced. Sixth, the works of laborers should be minimized and a computer technology that can easily and accurately design complicated forms or shapes of free-form concrete should be incorporated to such works [11].

The fundamental method of meeting the requirements described above is development of free-form molds that can be reused semi-permanently and where cost can be reduced. As illustrated in Fig. 5, the study manufactured a variable mold using PCM (Phase Change Material) and proposed a concept of producing concrete members. PCM is a substance that remains solid at a certain temperature and changes to liquid when heated. Unlike the other materials like water that demonstrate phase changes, it changes the phase at relatively low temperature difference, so it is suitable as the material of variable mold.

The production method of free-form concrete using a variable mold is divided into 4 stages as shown in Fig. 2. At the first stage, the design information is segmented and reorganized into FCS production unit (Fig. 6-a). At the 
second stage, PCM mold which can produce FCS is manufactured based on the information of FCS production unit (Fig. 6-b). At the third stage, FCS is manufactured using the PCM mold (Fig. 6-c) and the used PCM mold can be reused through a melting process. At the last stage, the manufactured FCS is lifted and installed (Fig. 6-d). The first three stages are continued without interruption, and the last stage that includes FCS installation is managed and controlled separately.

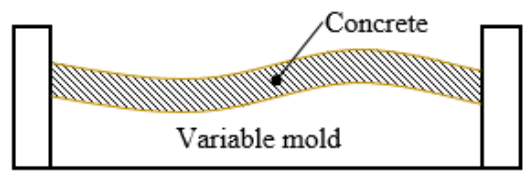

Fig. 5. PCM-applied variable mold.

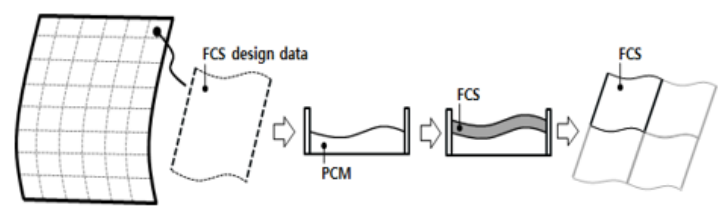

a. FCD design segmentation b. PCM Mold manufacturing c. FCS production d. FCS installation

Fig. 6. FCS Production Process using PCM Mold.

PCM mold is manufactured by first making a shape using NCR (Numeric Control Rod) that controls the height of mold and a rubber plate, and then heated PCM is injected and cooled. To perform the described work, equipment called $\mathrm{CNC}$ is devised as shown in Fig. 7, and it can be classified into an upper-type and a lower-type depending on the location of NCR. CNC can produce single mold per cycle, and it takes around an hour including PCM cooling time for production. Thus, it is believed that PCM mold is fairly effective in reducing the construction duration and cost when compared to existing technologies.

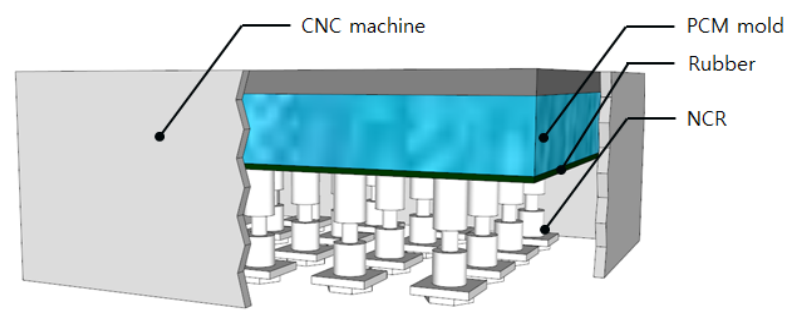

Fig. 7. Conceptual diagram on $\mathrm{CNC}$ machine for $\mathrm{PCM}$ mold manufacturing.

\section{CONCLUSION}

The study analyzed the technical requirements for production of free-form concrete and related problems so as to solve the problems of existing free-form concrete production methods. Also, the concept of developing production technology of free-form concrete that secures constructability and economic feasibility was proposed. The study results are as described below.

1) The existing production technologies of free-form members had several problems including long construction duration and use of temporary resources that cannot be reused or recycled and increase in cost for production of members. In addition, it is limited in realizing various shapes or forms, and it may result in reduction of member strength.

2) Some requirements of mold to solve the above-mentioned problems were the curing speed of concrete and its economic feasibility, accurate shape or form, strength that endures external pressure, reusability rate and variability.

3) The study proposed a technology of realizing free-form shapes by manufacturing the shape of PCM mold using $\mathrm{CNC}$ machine and pouring concrete on top of the PCM mold. After FCS is produced, PCM mold is liquefied to produce other shapes of members. In addition, the same-sized and -shaped FCS can be mass-produced to shorten the time required for manufacturing members. Thus, when PCM mold applied FC production is adopted, it is anticipated that it will solve problems related to cost increase, delay in construction and lowered productivity. The study result will be used as basic data for comparison/analysis studies on economic-feasibility and constructability of the existing molds and the improved ones, and for free-form concrete production to build free-form buildings.

\section{ACKNOWLEDGMENT}

This work was supported by the National Research Foundation of Korea (NRF) grant funded by the Korea government(MSIP)(No. 2008-0061908)

\section{REFERENCES}

[1] K. J. Bae, S. H. Lee, and H. J. Jun, “A Study on digital design process of the materialization of free form design architecture," Architectural Institute of Korea, vol. 29, no. 1, pp. 221-224, 2009.

[2] Nedcam. [Online]. Available: http://www.nedcam.nl.

[3] R. Schipper and B. Janssen, "Manufacturing double-curved elements in precast concrete using flexible mould-first experimental results," in Proc. fib Symposium PRAGUE, Vlastimil Šrůma ed, vol. 1, 2011.

[4] P. Mandl, P. Winter, and V. Schmid, "Freeforms in composite constructions - The new house of music and music theatre "mumuth," in Graz," Tagungsband Eurosteel, 2008

[5] B. Lindsey and D. Gehry, Material Resistance Digital Construction, Birkhauser, 2001

[6] Toyo Ito and Associates, Meiso no Mori Crematorium Gifu, 2006

[7] J. I. P. Latorre, "Construction method to build ice shells with pneumatic formwork," Master's Thesis, Vienna University of Technology Faculty of Civil Engineering, 2010

[8] R. W. A. Verhaegh, "Free forms in concrete fabric," MS thesis, Endhoven University of Technology, Aug. 2010.

[9] Y. M. Park, S. J. Jo, and S. J. Kim, "Development of the free-formed concrete structure construction technologies using 3D digital design," Autumn Annual Conference of The Korea Institute of Building Construction, vol. 12, no. 1, pp. 205-208, 2012.

[10] F. Architeckten and A. Architeckten. The Bubble. [Online]. Available: http:// www.franken-architekten.de

[11] G. H. Park, "The final goal of technological development is application," Construction Economy, Oct. 2010.

[12] S. H. Kwon, "A study on the identification of as-built quality control points for the free-form building façade panels," M.S thesis, Graduate School of Industry in Seoul National University of Science \& Technology, 2011

[13] Gidon Fuehrer. [Online]. Available: http://www.yatzer.com/Firstphotos-of-Spencer-Dock-Bridge-in-Dublin

[14] G. Lee, "Construction issues of irregular-shaped buildings," Journal of Architectural Institute of Korea, vol. 52, no. 4, pp. 63-65, 2008.

[15] Peri. [Online]. Available: http://www.peri.com/en/projects/projects/cultural-buildings/mercedesbenz-museum.cfm

[16] S. Y. Choi and J. K. Kim, "A study on the digital master model as a design process in digital architecture," Journal of Architectural Institute of Korea, vol. 25, no. 4, pp. 99-106, 2009. 
[17] Design to Production. [Online]. Available: http://www.designtoproduction.ch/content/view/17/26/

[18] N. Cauberg, B. Parmentier, M. Vanneste, and M. Mollaert, "Fabric formwork for flexible, architectural concrete," FRPRCS-9 Sydney, Australia, 2009.

[19] W. H. Kwon, "Control technology of automation and digital," Institute of Electrical Engineers, vol. 46, no. 7, pp. 84-87, 1997.

[20] Shoparc. [Online]. http://www.shoparc.com/\#/projects/all/camera_obscura

Available:

1] H. K. Lee, "A study on the tectonic meaning of architectural skin by the introduction of digital technology, focus on project of frank gehry and herzog and meuron," Master`s Thesis, SeJong University, 2008.

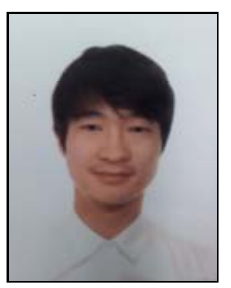

Donghoon Lee has concentrated on various areas of research such as health performance assessment of buildings, construction technology, project management, simulation and optimization for decision making.

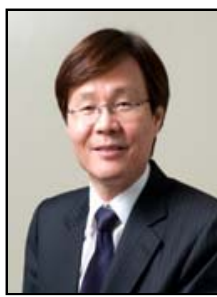

Sunkuk Kim majored in construction engineering and management. He has concentrated on various areas of research such as health performance assessment of buildings, construction technology, project management, simulation and optimization for decision making, Construction Information Technology.

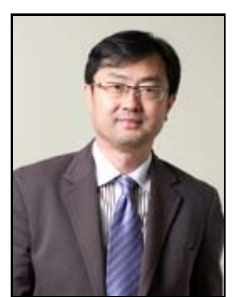

Won-Kee Hong received his master and $\mathrm{Ph} . \mathrm{D}$ degree from UCLA. He also has professional engineering license from both Korea and U.S.A. Professor Hong's research interests include a new approach to construction technologies based on value engineering and composite structures. He provided many useful solutions to the current structural design and construction technologies issues.

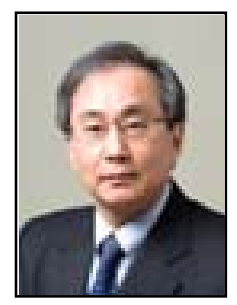

Jeong Tai Kim is a Kyung Hee Distinguished Fellow at Kyung Hee University and is a fellow of the Korea Academy of Science and Technology (KAST). In September of 2008, He founded the center for sustainable healthy buildings $(\mathrm{CSHeB})$ with the award of engineering research center (ERC) from Korea Government. As the director of the $\mathrm{CSHeB}$, he has tried to establish an outstanding R\&D center with global competitiveness by providing on-site research facilities, formulating synergistic interconnection with interdisciplinary researchers, and promoting collaboration and cooperation with various industries, government departments, and international universities. He also plays a key role in promoting sustainable healthy building technologies academically by hosting international symposiums, seminars, and workshops. He acted as the president of the Acoustical Society of Korea (2005), the Korea Institute of Ecological Architecture and Environment (2007-2008), and currently acts as the president of the Korea Society of Lighting and Visual Environment and the vice-president of the International Society of the Built Environment. 